Rev Soc Esp Dolor

2014; 21(1): 65-67

\section{Curso de Actualización en Dolor de la SED 2014}

\section{Sr. Director:}

Uno de los objetivos de la SED, y por tanto de su Revista, ha sido ofrecer al socio y al lector instrumentos para la formación continuada en dolor que contaran con el aval y la acreditación de los organismos correspondientes. Durante los pasados años la revista ha estado acreditada en su totalidad y de sus artículos se han extraído preguntas para los exámenes test que permitían obtener la acreditación.

La acreditación nos la otorgó la SEAFORMEC, que recientemente ha cesado en esta función, la cual ha sido asumida el Ministerio de Sanidad. Se nos ha comunicado un cambio en los procedimientos de acreditación para las revistas médicas de tal modo que ya no se acreditan revistas sino artículos.

Para dar respuesta a las solicitudes de formación continuada de los socios de la SED hemos diseñado un curso de formación continuada "on line", habiéndose solicitado por esta nueva vía la Acreditación a la Comisión de Formación
Continuada de las Profesiones Sanitarias. Será un curso de "Actualización en dolor de la SED" con una periodicidad anual. El material de estudio procederá de los artículos originales, revisiones, medicina basada en la evidencia y artículos relevantes de la Revista de la Sociedad Española del Dolor.

La sistemática será la misma que tuvimos en las pasadas ediciones de la Formación Continuada de la revista de la SED; si bien, hemos adaptado la plataforma de formación continuada para que el material de estudio esté colgado en dicha plataforma y sea de fácil acceso. Habrá que superar un examen test para poder obtener el certificado del curso.

Este curso será para los Socios de la SED y sin costes. El número de alumnos admitidos será limitado y por orden de inscripción.

V. Mayoral Rojals, L. M. Torres Morera, J. L. Ortega García y F. Neira Reina Directores Docentes del Curso de "Actualización en Dolor de la SED 2014" 